\title{
Trayectoria de la usura y el lucro en el judaísmo
}

Path of the usury and the profit in the Judaism

\begin{abstract}
Dr. Mario Matus G. mmatus@uchile.cl Universidad de Chile Chile

\section{RESUMEN}

Este trabajo sigue la evolución de la actitud hacia el préstamo de dinero con interés dentro del mundo judío, inserta dentro de una sucesión de pronunciamientos de muchas civilizaciones del mundo antiguo y antes de que el Cristianismo medieval irrumpiera con una posición condenatoria extrema. Esta revisión revela el importante grado de dinamismo y fluctuación de los sistemas de creencias ante esa práctica económica y enfatiza como el sistema legal mosaico fue elaborando razonamientos cada vez más sofisticados ante ella, basados en una jurisprudencia de tipo casuístico.
\end{abstract}

Palabras clave: Usura, préstamo de dinero con interés, Judaísmo.

\begin{abstract}
This paper traces the evolution of attitudes towards borrowing money with interest within the Jewish world, inserted into a succession of pronouncements of many civilizations of the ancient world and before the burst medieval Christianity with extreme sentencing position. This review reveals the high degree of dynamism and fluctuating belief systems to the economic practice and emphasizes how the legal system was prepared mosaic increasingly sophisticated reasoning to it, based on a case-type case.
\end{abstract}

Keywords: Usury, loans, Judaism. 


\section{INTRODUCCIÓN}

Desde los albores de la humanidad todas las civilizaciones han debido pronunciarse sobre la legitimidad y legalidad del préstamo de dinero con interés usando sus estructuras de valores y sus sistemas normativos. En esa tarea, a las religiones les cupo una enorme influencia, y entre todas las religiones, las que impusieron una impronta categórica fueron las llamadas religiones abrahámicas, es decir, aquellas que nacieron al alero o bajo la influencia de la Torá judía y que su vez, son los fundamentos del mundo occidental ${ }^{1}$.

De tal modo, revisar la trayectoria del tema del préstamo de dinero con interés en la primera de estas tres religiones devela complejos procesos de transición en los que se vertebran intrincadas interacciones entre el ámbito de las creencias y el de la vida material. Procesos que implican importantes grados de conflicto y requieren sofisticados aprendizajes para articular equilibradamente logros económicos con una perspectiva humanista de la vida. Así es porque en el trasfondo de la actitud ante la llamada "usura" está la fundamental discusión sobre la legitimidad y los límites del beneficio o ganancia, o como a los estudiantes chilenos desde 2011 en adelante les gusta denominar: el lucro. En definitiva, explorar los dilemas éticos que sostuvieron la condena a la usura como las transformaciones económicas que los condicionaron ofrece interesantes aristas a nuestro propio debate acerca del necesario equilibrio entre beneficio y equidad. Este artículo se concentra en la trayectoria del concepto de usura en el judaísmo, dado que fue en esta religión en particular, y cultura en general, donde aparecieron los primeros pronunciamientos sistemáticos acerca del préstamo de dinero con interés. En las líneas que siguen se examina la evolución del término usura, la percepción del préstamo de dinero con interés en civilizaciones anteriores o contemporáneas a la hebrea, la actitud inicial del judaísmo ante el préstamo de dinero con interés, las condiciones que llevaron a su endurecimiento, las condiciones posteriores que llevaron al judaísmo a una incipiente aceptación del préstamo de dinero con interés, el surgimiento de la condena cristiana a la usura, y finalmente, la

\footnotetext{
${ }^{1}$ Basta aquí recordar que el nombre utilizado en castellano para el dinero es una derivación de la palabra "dinar" que designaba la principal moneda árabe en la época medieval.
} 
formalización del préstamo de dinero con interés al interior del judaísmo. Las conclusiones recogen los problemas y aspectos más centrales.

\section{Evolución del término usura}

Las diversas que la Real Academia Española asigna a la voz "usura" en su Diccionario de la Lengua Española" insinúan su polisemia histórica:

"Usura. (Del lat. Usura).

1. f. Interés que se lleva por el dinero o el género en el contrato de mutuo o préstamo.

2. f. Este mismo contrato.

3. f. Interés excesivo en un préstamo.

4. f. Ganancia, fruto, utilidad o aumento que se saca de algo, especialmente cuando es excesivo".

(Real Academia Española, 2012).

En efecto, en idioma castellano el vocablo usura abarca desde un interés excesivo aplicado a un préstamo (sentido restringido) hasta cualquier interés asignado a diversos tipos de contrato (sentido amplio) e incluso, cualquiera ganancia, utilidad o beneficio (lucro) que se obtenga de algo, especialmente cuando es excesivo (sentido más amplio). Cuando se usa como verbo (usurar: dar o tomar usura) o como adjetivo (usurero: persona que presta con interés excesivo o personas que en otros contratos obtienen lucro desmedido) se convierte en un término que puede usarse para designar cualquier conducta económica reprochable.

Pero más allá del uso equívoco y popular del concepto, en términos estrictos usura se define actualmente como la acción de "Cobrar unos tipos de interés "excesivos" o "irrazonables" sobre los préstamos" (Seldon y Penance, 1987). Y ese es el sentido que hoy se le da al término usura. No se trata de cualquier tipo de préstamo o de contrato al que se le aplica algún tipo de interés, sino sólo de aquellas operaciones gravadas con un interés demasiado oneroso, que generan un beneficio exagerado al prestamista y un perjuicio importante al prestatario. Por otra parte, hoy también se enfatiza que la usura normalmente es ejercida de modo ilegal, es decir, por personas u organizaciones que no cumplen con la ley y, que por el mismo hecho, pueden usar formas 
violentas para cobrar intereses muy desmedidos. Por consiguiente, en la actualidad el carácter injusto de la usura se deriva de si el prestamista está autorizado para ejercer su actividad o si se trata de una operación al margen de la ley y de la que emerge una tasa de interés demasiado elevada. Por consiguiente, la mayoría de los gobiernos de diversos países penalizan como delito de usura el cobro de intereses excesivos, por sobre los límites establecidos por la ley (KunickaMichalska, 1994).

Así y todo, la Iglesia Católica tardó hasta el siglo XIX para abandonar oficialmente la condenar de todo tipo de préstamo de dinero con interés y el Islam aún no lo ha hecho.

Cabría entonces preguntarse por qué el Judaísmo adoptó tan tempranamente la prohibición del préstamo de dinero con interés y en su forma más amplia. Pero también cabría interrogarse por qué también fue más temprano su abandono y su transición al sentido más restringido que hoy prevalece. Para entenderlo, cabe insertar la trayectoria de la actitud del judaísmo dentro de un contexto histórico anterior.

\section{La usura en la antigüedad}

Las primeras noticias del préstamo con interés (aplicado a dinero o bienes) no muestran una condena. Hacia 1760 aEC., el artículo 71 del Código de Hammurabi -primera ley conocida sobre el particular- establecía que se perdería el derecho a recobrar el préstamo si se sobrepasaba el máximo legal permitido al tipo de interés y castigaba el abuso de intereses con la pérdida de la deuda. El Imperio Babilónico aceptaba el crédito en la medida que lo concebía como un resorte esencial de su vida económica (Gelpí y Julien-Labruyere, 1998).

En la Antigua India las referencias al préstamo con interés tampoco eran condenatorias per se. Si bien hay referencias críticas a ella en el llamado Rig-veda (2000 y 1400 aEC), en los Sutras (entre 700 y 100 aEC) y en los Yatakas budistas de 600-400 aEC (Visser and McIntosh, 1998), ya en las llamadas Leyes de Manu hacia 200 aEC estas críticas se fueron circunscribiendo al cobro de interés por sobre lo que estipulaba la ley: "8.141. "[el prestamista], consciente de los hábitos de las personas humanas, puede pretender [como interés] el dos por ciento [al mes]; el que toma el dos por ciento no comete el pecado de usura" ... o ... "8.152 "Un interés pactado que 
sobrepase el límite legal, siendo contrario [al dharma], no es válido y se le llama usura" (Dell' Aquila, 1992). De modo que hacia 200 aEC tampoco existía una condena o prohibición genérica desde el Budismo.

Por su parte, en el Antiguo Egipto también se aceptaba el préstamo con interés siempre que la tasa no sobrepasara cierto límite legal. Una ley de Asychis -supuesto monarca de la IV dinastíaobligaba al prestatario a asegurar el pago de la deuda entregando en prenda la momia del padre $\left(\right.$ Castillo, 2007) ${ }^{2}$. Así las cosas, cuando el Judaísmo se hizo cargo de este problema existía una voluminosa doctrina jurídica (Babilónica, India y Egipcia) que no prohibía el préstamo con interés sino más bien tendía a regularlo y a establecerle límites.

\section{Primeras percepciones mosaicas hacia la usura}

Al comienzo, el Judaísmo siguió este mismo camino. En las tradiciones orales -que podrían remontarse a inicios del II milenio o a fines del I milenio aEC- y que se recogen en el Decálogo (Diez Mandamientos; supuestamente compilados hacia el siglo $\mathrm{X}$ aEC), y en general, en el Pentateuco (que habría sido codificado hacia el siglo VII aEC, según los fragmentos más antiguos de la Torá) el cobro de intereses parece haberse cuestionado sólo cuando se aplicaba a préstamos dirigidos a los pobres o a personas en apuros económicos: "Si tú prestas dinero a uno de mi pueblo, al pobre contigo, no te portarás con él como un acreedor (nosheh), ni le cobrarás intereses" (Éxodo 22:25). "Si tu hermano empobrece y recurre a ti, tú lo ampararás; como forastero y extranjero vivirá contigo. No tomarás de él interés ni ganancia, sino tendrás temor de tu Dios, y tu hermano vivirá contigo. No le darás tu dinero con interés ni tus víveres a ganancia" (Levítico 25:35-37). Sin embargo, el Judaísmo decidió tomar un camino distinto quizás hacia el siglo VII aEC (época a la que correspondería el Deuteronomio) ${ }^{3}$ cuando aplicó la prohibición a todos los préstamos de dinero, excluyendo sólo a los negocios con los extranjeros.: "No exigirás

\footnotetext{
${ }^{2}$ Castillo obtiene esa información de Gómez del Campillo, Francisco (1893). Consideraciones sobre el derecho egipcio. Revista General de Legislación y Jurisprudencia. P. 300.

${ }^{3}$ Que habría sido encontrado o escrito en el reinado de Josías (639-608 aEC), rey que en 622 aEC dictó un código que liberó a los esclavos por deudas, treinta años antes de que lo hicieran las leyes de Solón en Atenas.
} 
de tu hermano interés por el dinero, ni por los comestibles, ni por cosa alguna de la que se suele exigir interés. A un extranjero podrás exigir interés, pero de tu hermano no lo exigirás; para que te bendiga Jehová, tu Dios, en toda la obra de tus manos, en la tierra que vas a entrar para tomarla en posesión" (Deuteronomio 23:20-21). En esta nueva formulación legal, era indiferente si el interés era excesivo o no; bastaba con que hubiera un interés.

La definición deuteronómica dio lugar a diversos debates en torno a los dos términos usados en la Torá para significar préstamo con interés: neshekh y tarbit (o marbit). Estos debates fueron interpretados en la Mishná (tradición oral posterior a la Torá, codificada alrededor del año 200 dEC) y posteriormente fueron tratados en la Guemará (comentarios que junto a la Mishná constituyen el Talmud $)^{4}$. Se consideró que el punto de vista más autorizado fue el de Rava ${ }^{5}$, que sostuvo que en la Torá no existía diferencia alguna de significado entre neshekh y tarbit (Baba Metsia 60b) y las dos palabras eran sinónimos que enfatizaban a los destinatarios de la prohibición (al prestamista o al prestatario). De ahí que por el lado etimológico neshekh (mordida), se habría utilizado para expresar la exacción del interés desde el punto de vista del deudor, mientras que tarbit o marbit, (incremento) se orientó a la recuperación del interés por el acreedor (Encyclopaedia Judaica, 2007). Pero incluso hasta ese punto, la práctica no era considerada un delito, sino más bien una transgresión ética, y por lo tanto, no estaba sujeta a sanción penal. En cualquier caso, si alguien prestaba sin pedir devolución y sin exigir intereses, obtendría la recompensa divina. Por otro lado, la prohibición no adquiría un carácter universal, ya que podía prestarse con interés a quienes no fueran "hermanos" (no hebreos, gentiles) ya que a ellos, en general, no se estaba obligado a ayudar ${ }^{6}$.

\footnotetext{
${ }^{4}$ Se ha usado la versión castellana del Talmud de Babilonia -culminado alrededor del siglo V dEC. - y que es el más aceptado por la tradición mosaica. El Talmud de Jerusalem habría sido compilado hacia el año 400 dEC. Baba Metsia es uno de los tratados comprendidos en el Nezikin (orden cuarto, relativo a los daños). 5 270-350 dEC.

${ }^{6}$ Hacia el siglo VII aEC- en que se constata este cambio de actitud ante el préstamo de dinero con interéslos reinos de Judá e Israel se situaban entre dos grandes imperios (Asirio por el Este y Egipcio por el Sur) y al menos entre otros tres pueblos (Hititas y Fenicios por el norte y el noroeste respectivamente; y Pueblos del Mar o Filisteos al suroeste). De ahí que la formación de una fraternidad tribal en oposición al "otro" fuera relativamente explicable no sólo en el caso de los judíos sino también en todos los otros pueblos mencionados.
} 


\section{Endurecimiento del judaísmo ante la usura}

Sin embargo, los acontecimientos posteriores al siglo VII aEC trastornaron esta actitud algo indulgente. Luego de ocupar las tierras de Canaán hacia el año 1.400 aEC, los judíos establecieron una monarquía, consolidaron ciudades y establecieron el reino unido de Judá, con capital en Jerusalén. Pero luego del reinado de David y de su hijo Salomón se formaron dos reinos (Israel al norte y Judá al sur), permanentemente amenazados por el Imperio Babilónico, y que fueron conquistados por él en 720 y 586 aEC respectivamente. Fuera de los problemas externos, aparecieron grandes fracturas internas. Luego de tomarse de los cananitas el préstamo de dinero con interés entre muchas otras costumbres, éste fue aplicado a un numeroso contingente de campesinos, que al no poder pagar sus deudas, perdieron sus tierras, quedaron obligados a trabajar para el acreedor por al menos seis años, y finalmente, se convirtieron en jornaleros sin tierras. Para atenuar esa situación, hacia el siglo IX aEC se promulgó un compendio de Leyes Civiles -incluidas en el Libro de la Alianza- que prescribió la liberación del esclavo hebreo por deudas luego de seis años de trabajo. Desafortunadamente para el Reino de Judá, sobrevino la conquista babilónica por Nabucodonosor, la destrucción del Primer Templo el año 587 aEC y el largo cautiverio de la élite gobernante en Babilonia.

Ya en Babilonia, profetas como Ezequiel (que probablemente escribió en el siglo VI aEC) interpretaron que la derrota y el cautiverio se explicaban por todas las injusticias y el alejamiento de la fe que habrían caracterizado al Reino de Judá. Quedaba la sensación de que el poder de los gobernantes y sacerdotes del Templo había corrompido a todo el pueblo hebreo y que era imperativo recuperar la integridad y la devoción como base para restaurar el pacto con D's. Especialmente, Ezequiel insistía en que habían sido los mismos individuos los que se habían corrompido (Johnson, 2006), por lo que se requería aplicar un programa moralizante que implicaba endurecer algunas prohibiciones. Una de las más importantes se vinculaba al préstamo de dinero con interés, práctica a la que se adjudicaba el socavamiento de la cohesión social y se le imputaba ser causa de muchos males. 
Así fue como en las profecías de Ezequiel la usura fue identificada con el más grave de todos los crímenes. Se la mencionaba a la par del latrocinio, adulterio, homicidio y otras "abominaciones" dignas de muerte (18:11-13) ${ }^{7}$. Más tarde, la amenaza de muerte por usura fue interpretada como sanción divina contra el enriquecimiento ilegítimo e irreversible (Baba Metsia 61b). "El que aumente su sustancia por el interés y la ganancia es ubicado junto a los "hombres diabólicos" (Proverbios 28:8), mientras que "aquel que no impone a su dinero interés" es uno de los rectos y justos (Salmos 15: 5).

Pero las circunstancias del cautiverio no fueron especialmente favorables para el endurecimiento de la prohibición. Los cautivos hebreos prosperaron y se vieron obligados a multiplicar sus relaciones de crédito al interior del grupo. Por otro lado, aunque aún no existía una teoría monetaria moderna que explicara el origen y los efectos de la inflación, la existencia de sistemas monetarios reales (no fiduciarios) en la antigüedad no impedía la existencia de una inflación de precios, que normalmente se expresaba en emisión de monedas con menor contenido de metales nobles. De ahí que una deuda de 100 valía más que ese valor al momento de ser cancelada y si no se agregaba un interés que asumiera la pérdida de valor del dinero -o lo que es lo mismo, la inflación disfrazada tras ello- el prestamista en los hechos se empobrecía en favor del prestatario. De tal modo, las necesidades económicas de la comunidad y la percepción intuitiva de que el dinero perdía valor, obligaron a relajar la prohibición por medio de subterfugios legales que de algún modo lograban conservar su espíritu original. Por lo demás, éste era el procedimiento histórico que el Judaísmo utilizaba para adaptar la Halajá (Ley) a las circunstancias históricas, que normalmente dejaban atrás el sentido formal de los preceptos.

En esa misma época y un poco del cautiverio de los judíos en Babilonia, el préstamo de dinero con interés era permitido en la Antigua Grecia y de ello dan cuenta las reformas promovidas el año 594 aEC. por Sólon, quien abolió la esclavitud por deudas y devolvió las tierras a sus antiguos propietarios. El endeudamiento se había transformado en una de las pocas vías por la que los campesinos empobrecidos podían seguir cultivando, pero en caso de fracasar, perdían sus

\footnotetext{
${ }^{7}$ Las referencias a capítulos y versículos no varía dependiendo de la edición. Por ello, para ésta y posteriores citas de la Torá .sólo se entrega su localización genérica adscrita a cada libro.
} 
tierras y se convertían en esclavos en manos de terratenientes prestamistas. Por otro lado, los templos griegos competían ofreciendo intereses más bajos, lo que no impedía que la tasa de interés fuera bastante alta (cercana al 24\% mensual).

Posteriormente, luego que Ciro II (El grande) conquistara Babilonia el año 537 aEC., permitió a los hebreos volver a Jerusalén. Así éstos recuperaron su autonomía y la mantuvieron hasta el año 63 aEC, cuando Pompeyo conquistó la región y la convirtió en provincia tributaria de Roma. Fue durante ese largo período que va entre 537 y 63 aEC que se terminó de compilar el Talmud y que el debate sobre la prohibición del préstamo con interés volvió con nuevos bríos. Ello se reflejó en una notable ampliación de la prohibición hacia todo tipo de transacción en que se percibieran beneficios que encubrieran algún tipo de interés (alquileres, préstamo de víveres, semillas). Incluso se llegó al extremo de prohibir que dos hombres trabajaran para su propio beneficio en turnos en dos tipos distintos de faenas, ya que al ser una de ambas tareas más valiosa que la otra, uno de los dos acumularía mayor beneficio. Los mismos regalos que un hombre podía entregar a otro -pensando en el futuro pedirle un préstamo o como posterior agradecimiento a su recepcióncomo así también las palabras de saludo, fueron cuestionados porque propiciaban el préstamo con interés. Un acreedor hipotecario no podía tomar el producto de ese bien inmueble, incluso estando en su posesión, y si lo hacía, debería deducirlo de la deuda de capital. Se rechazó el interés incluso en la compraventa de todo tipo de bienes, a menos que su precio de mercado estuviera exactamente establecido, en la idea de evitar que un comprador adquiriera beneficios ilegítimos al realizar compras adelantadas con precios menores a los de mercado (compras en verde). Una última esfera a la que se amplió la prohibición fue la constitución de sociedades, para impedir que un socio financista compartiera los beneficios pero no las pérdidas, que podían perjudicar sólo al socio gestor. Con ese fin, se estipuló la sociedad sólo sería válida si ambos compartían beneficios y pérdidas y el financista pagaba un sueldo al socio gestor (Ben-Zion Eliash, 2007).

Todas estas ampliaciones a la prohibición original fueron conocidas como Avak ribbit, (polvo del interés) a diferencia del ribbit kez̧uzah, el interés que correspondía propiamente a un préstamo. 
La diferencia no era menor, ya que en el segundo caso el prestatario tenía derecho a recuperar el pago cuestionado.

Como puede verse, el problema específico del préstamo con interés se inscribía dentro de un ámbito mucho más amplio, que era el tema de los límites que debían fijarse al beneficio, ganancia (o lucro) con el fin de proteger el bien común, situación que había sido captada en toda su magnitud durante el cautiverio en Babilonia. Y para lograr ese objetivo no solamente se debía vigilar el beneficio, sino que además debía normarse y aplicarse la justicia laboral y debía protegerse la competencia. Había que proteger el buen funcionamiento de los mecanismos de mercado (impidiendo la concentración económica) pero también intervenir en ciertas esferas donde el funcionamiento de los mecanismos de mercado generaba asimetrías y efectos sociales perversos. "En adelante, toda la doctrina económica apunta a fijar las mejores condiciones de supervivencia del grupo en un medio extranjero. Se basa en tres principios: trabajo, competencia, solidaridad. También puede enunciarse de este modo: cada miembro de la comunidad debe trabajar para ganarse la vida, de conformidad con los principios éticos planteados por la Ley, de ser posible en un oficio libre y solitario; cada cual debe aceptar la competencia, lo que le permite tener la posibilidad de hacer fortuna, pero también le hace correr el riesgo del fracaso, y torna necesaria la solidaridad. Por último, cada uno debe cuidarse de no perjudicar al grupo a los ojos de terceros e incluso, si puede, ser útil a los anfitriones que los reciben" (Attali, 2006). Esto es lo que explica que se limitara a un $15 \%$ el beneficio o utilidad en actividades económicas entre judíos -que era más o menos lo mismo que se debía tributar al Templo-, que se impusiera obligación de trabajar y se condenara la pereza y el vagabundaje, y finalmente, que se estipulara colaborar con un $10 \%$ de la renta (diezmo) a la comunidad, y al mismo tiempo, brindar Tsedaka (ayuda) a los más necesitados, incluyendo a extranjeros que lo requirieran. En el entrecruce de estos tres principios básicos de comportamiento económico se situó el problema del "justo precio", que subyacía a ellos..

Un ejemplo de la preocupación manifiesta por la justicia en los procedimientos comerciales aparece en una de las muchas discusiones del Talmud. Según la Mishná, los comerciantes mayoristas tenían que limpiar sus medidas cada treinta días, dado que los restos de líquidos 
grasos -como el aceite- se adherían a las paredes de las medidas y reducían su capacidad. En cambio, los dueños de casa, que las usaban mucho menos, debían hacerlo sólo cada doce meses. Pero incluso esto era discutible. El rabán Shimeón ben Gamaliel $^{8}$ afirmó que en la práctica se daba más bien al revés, dado que en las medidas usadas con más frecuencia se pegaba menos la grasa. Así, los tenderos minoristas limpiaban las medidas dos veces por semana, ya que las usan más que los mayoristas. Del mismo modo, frotaban las pesas una vez por semana y limpiaban la balanza cada vez que la usaban. Así y todo, el mismo rabán Shimeón ben Gamaliel señaló que estas normas sólo debían regir para los [artículos] húmedos, ya que con los secos no hacía falta aplicarlas. [88b]. Por otra parte, los comentaristas de la Mishná señalaron que si el tendero inclinaba el platillo de la mercadería un palmo más que las pesas, era su obligación agregarle al producto un décimo si se trataba de líquidos o un vigésimo si eran productos secos (Weiss, Talmud, Tratado Baba Batra).

Algunos autores han sostenido que el énfasis en esa solidaridad de grupo arranca de una "hermandad tribal" que implicaba una ética distinta hacia otros pueblos, hacia los que se definía en oposición. Esto habría sido común a todos las sociedades humanas hasta el período medieval (específicamente hasta el siglo X), en que por primera vez comenzó a atisbarse una concepción de "hermandad universal" a partir del Cristianismo (Nelson, 1969). Probablemente, la actitud de "hermandad tribal" se acentuó en el caso de los judíos porque brotó muy tempranamente y luego adquirió una gran intensidad, a causa de su enorme vulnerabilidad externa ante la posibilidad de avasallamiento o exterminio por parte de otros pueblos.

Esto es lo que explicaría que:

Aun de forma sumamente compleja, un cierto principio religioso de fraternidad, proscriptivo de la explotación mediante la economía, imperaba en esta sociedad; regía realmente una fraternidad religiosa a la que repugnaba la mera idea de que se produjesen transferencias de valor o efectos de expropiación por la actividad puramente económica en cualquiera de sus

$810 \mathrm{aEC}-70 \mathrm{dEC}$. 
formas o expedientes. Es difícil ciertamente de reconocer a primera vista esta fraternidad en la sociedad bien conflictiva, muy discriminatoria y no poco mercantilizada de la época, pero sus teóricos más orgánicos se empeñan en predicarla y, lo que es desde luego más importante, sus instituciones, también las económicas, responden realmente, aunque de forma no siempre primaria, a sus imperativos (Clavero, 1984).

Mientras la sociedad judía afianzaba los principios éticos internos que le daban un nuevo impulso a la prohibición de prácticas que generaban "precios injustos", Roma vivía problemas sociales no muy diferentes derivados de la esclavitud por deudas. Por ello, la República se vio obligada el año $450 \mathrm{aEC}$ a fijar en las llamadas XII Tablas una tasa límite de un 8,3\% mensual. Posteriormente, las llamadas Leyes Licinias (376 aEC) otorgaron la remisión de los intereses y una moratoria de tres años para devolver la deuda a los deudores insolventes. La pena de muerte, que podía ser aplicada a los deudores insolventes, fue desvinculada a las deudas por la Ley Poetelia Papiria el año 326 aEC. (Gelpí y Julien-Labruyere, 1998; 36). Tanto en Grecia como en Roma el préstamo con interés -uno de los principales ingresos de las familias aristocráticas y de instituciones laicas y religiosas- había causado profundos estragos sociales. Pero así y todo, allí el acento no estuvo puesto en su eliminación, sino más bien en la limitación de su tasa para evitar excesos.

Mientras tanto, el Imperio Carolingio y el Imperio Bizantino habían adoptado las enseñanzas de un rabino judío llamado Jesús, crucificado durante el reinado del Emperador Tiberio. Pero incluso con la irrupción del Cristianismo bajo Constantino el Grande (272-337 dEC) aún no predominaba una prohibición del préstamo con interés. Aunque el temprano Cristianismo dictó unas primeras leyes sobre la usura en el Concilio de Arles (314 dEC), la práctica siguió su curso normal. Sólo el año $325 \mathrm{dEC}$. Constantino convocó oficialmente al Primer Concilio de Nicea, en la idea de institucionalizar la Iglesia y organizar la doctrina cristiana para evitar el resquebrajamiento del Imperio. Así, mediante ese concilio se expulsó a los cléricos que prestaban con interés. Pero cuando Padres de la Iglesia -como Ambrosio (fallecido en 397 dEC), Jerónimo 
(fallecido en 420 dEC) y el Papa León (muerto en 461 dEC)- llamaron a una prohibición universal, Constantino fue renuente a romper una práctica comercial romana legal. De ese modo, confirmó la tasa máxima tradicional de 12\% al año (Armstrong, 2003).

Luego que cayó el Imperio Romano de Occidente el año 476 dEC, el Emperador de Oriente Justiniano logró reconstruirlo momentáneamente durante el siglo VI dEC. Una vez más, aunque la temprana Iglesia Cristiana se lo solicitó, el Código Justiniano -promulgado el año 529 dEC- no abolió el interés y sólo redujo la tasa al límite de 6\% para los préstamos comerciales ordinarios entre particulares, al $4 \%$ para préstamos de consumo y al $8 \%$ para transacciones desarrolladas por banqueros y comerciantes (Armstrong, 2003; Gelpí y Julien-Labruyere, 1998). Pero aunque el préstamo con interés siguió siendo legal en Bizancio, luego del cisma religioso entre la Iglesia Católica Romana y la Iglesia Católica Ortodoxa en el año 1054 dEC, la Iglesia Cristiana Ortodoxa adoptó la prohibición. La marcha hacia la prohibición se fue afianzando en la Europa cristiana, oriental y occidental.

Pero mientras los cristianos habían dejado de ser perseguidos por el Imperio Romano y como nuevos actores políticos influyentes se habían transformado en uno de sus más importantes soportes, el reino de Judea había desaparecido. Una vez que el territorio fue ocupado por las legiones romanas y fue transformado en provincia, sobrevino un primer gran levantamiento en 66 dEC, qué culminó con la matanza de la población de Jerusalén y la destrucción del Segundo Templo por el general Tito el $70 \mathrm{dEC}$. En esas circunstancias, se le permitió al rabino Yochanan ben Zakai establecer la academia de Yavné, que tuvo un rol fundamental en la tarea de recopilar la Halajá. Pero la situación empeoró con un nuevo levantamiento contra los romanos en $113 \mathrm{dEC}$ y otro posterior el año $132 \mathrm{dEC}$ (la llamada rebelión de Bar Kojbá) que luego de sostener a Israel como estado independiente durante tres años, fue sofocado brutalmente con nueve legiones. Con el exilio de la población superviviente y la destrucción de prácticamente todos los centros poblados, Babilonia se transformó en el principal núcleo judío, mientras que todo el resto de los exiliados iniciaron una prolongada Diáspora a lo largo de toda Europa y todo el borde mediterráneo. 


\section{Gradual aceptación del préstamo de dinero con interés}

En esas circunstancias, los judíos de la Diáspora debieron hacer transformaciones profundas al interior de sus comunidades para mantener su identidad. En ausencia de gobernantes y de las autoridades del Templo, el Judaísmo se replegó hacia las sinagogas repartidas por toda Europa y el mundo mediterráneo y hacia el interior de los hogares. Junto a esas medidas desesperadas, debieron también adaptarse principios básicos de supervivencia, necesarios para vivir en los intersticios de otras sociedades:

Tanto en Palestina como fuera de ella, las comunidades reanudan los lazos con las viejas reglas elaboradas en el tiempo de la primera estadía en Babilonia: trabajar duro, no confiar más que en los suyos, transmitir a las generaciones futuras una lengua y una Ley, obedecer al príncipe del país de acogida, permanecer agrupados, comunicarse entre las comunidades (Attali, 2006).

Al mismo tiempo, debieron establecer dos instituciones en cada una de las comunidades. Un Consejo de Notables, que se encargó de administrar los cementerios, recaudar impuestos para pagar el fiscus judaicus ${ }^{9}$, apoyar a los pobres y desvalidos y negociar el rescate de los esclavos. En paralelo, se estableció un Tribunal Rabínico (Bet din), cuya jurisdicción sólo regía para los miembros de esa comunidad y se preocupaba de reglamentar precios, remuneraciones, tarifas de transporte y comisiones, de mediar entre empleados y empleadores para fijar salaros y precios mínimos, controlar pesos y medidas, verificar la aplicación embrionaria de un derecho laboral, asignar calles especiales a los cuerpos de oficios, administrar las mutuales de seguridad de los artesanos y canalizar las relaciones con los gentiles. Junto a estas entidades básicas, fue imperiosa la existencia de una sinagoga, un cementerio, baños rituales, comedores populares y otras entidades benéficas. En suma, la vida cotidiana de las comunidades judías de la Diáspora se anticipó varios siglos a la creación de un Estado de Bienestar, que en este caso, se incrustó en el

9 Pago anual que cada comunidad debía entregar al Imperio Romano. 
interior de cada sociedad de acogida y tuvo como fin supremo permitir la supervivencia. Y fueron esas mismas razones las que obligaron a revaluar la prohibición del préstamo de dinero con interés, incluso entre judíos.

Durante el período medieval, en el que la tierra sólo podía pertenecer a señores feudales o eclesiásticos y en el que no se aceptaba que judíos tuvieran trabajadores cristianos, era muy difícil que ellos pudieran ser señores propietarios plenos. Además, el cumplimiento de prescripciones religiosas como el Shabbat (no trabajar desde la puesta del sol en viernes hasta el crepúsculo del sábado) y la Kashrut (preceptos alimenticios) imposibilitaba que pudieran ser siervos de señores cristianos. Por esa razón, se les encontraba muy excepcionalmente como arrendatarios agrícolas. Por otro lado, si bien podían desarrollar actividades artesanales muy cualificadas (orfebrería, joyería, sedería y fabricación de objetos muy refinados) tuvieron crecientes problemas para integrar gremios o corporaciones menestrales, de las que finalmente fueron expulsados en la mayoría de los territorios europeos. Así, los artesanos judíos debieron resignarse a ser pocos y a habitar dentro de los márgenes de las juderías, imposibilitados de ofrecer sus productos fuera de ellas. Por consiguiente, fueron en su mayoría limitados a lo que hoy llamamos sector terciario (servicios) y entre ellos, sólo a aquellos cuyo ejercicio no estaba prohibido a cristianos. Uno de esos casos fue el del ejercicio de la medicina, debido a que no se les aplicaba la prohibición de diseccionar cadáveres, lo que si sucedía con cristianos. Tampoco se les vedó el rol de agente comercial, es decir, de intermediarios entre distintos mercaderes judíos y gentiles, para lo que tenían enormes capacidades heredadas: uso de la contabilidad por partida doble, conocimiento de las matemáticas -especialmente el cálculo de la tasa de crecimiento compuesto o interés-, conocimiento de varios idiomas, amplia inserción dentro de una vasta red de comerciantes congéneres dispersos por toda Europa y territorios del Islam y posibilidad de viajar periódicamente entre ambas zonas.

\section{Endurecimiento cristiano y aceptación mosaica}

En medio de todo esto, reyes, nobleza, comerciantes, artesanos y campesinos prósperos requerían de ingentes créditos, en la medida que se reanimaban las economías medievales estimuladas por 
la gran recuperación de los intercambios a partir del siglo X. Pero no existían medios de pago suficientes para colmar esas necesidades ya que se necesitaba mucho más crédito del que se había requerido hasta entonces. Esta creciente necesidad se topaba con un obstáculo, en tanto se había logrado instalar la prohibición civil -ya no sólo eclesiástica- del préstamo de dinero con interés dentro del mundo cristiano ${ }^{10}$. En efecto, hacia 789 dEC. Carlomagno presentó en Aquisgrán una resolución capitular conocida como Admonitio Generalis. En ella, el Emperador estableció que las actividades económicas no debían perturbar el orden divino y debía prevalecer un espíritu caritativo. De tal modo, allí se fijaron medidas moralizadoras sobre las transacciones y el uso del dinero que se convirtieron en modelo de muchas legislaciones posteriores. Fue así como se estableció por primera vez la prohibición civil de usura para los laicos, recogiendo lo que había sido solicitado por el Concilio de Clichy, celebrado el año 626.

Estas crecientes barreras al ejercicio del préstamo de dinero con interés no impidieron que los cristianos pudieran ejercer como prestamistas. De hecho, los banqueros lombardos italianos y muchos jerarcas de la Iglesia fueron activos agentes de crédito ${ }^{11}$. Del mismo modo, los banqueros mercaderes -que enviaban capital a sus socios- y los cambistas -que proporcionaban servicios de cambio y de depósito- lograron evadir la prohibición mejor que los prestamistas, debido a que sus actividades estaban confinadas a círculos reducidos y ocultas bajo transacciones lícitas, como la letra de cambio. Pero normalmente estos prestamistas volcaban su acción hacia grandes prestatarios, por lo que pequeños créditos entregados a comerciantes, artesanos y campesinos quedaban en manos de prestamistas judíos, razón por la que seguramente quedó en el imaginario popular que los únicos prestamistas medievales eran judíos ${ }^{12}$.

A la necesidad de los gentiles por ampliar la oferta de crédito y al callejón sin salida al que habían enviado a los judíos para subsistir, se agregó la necesidad de facilitar el crédito entre los mismos judíos, que habían construido una densa red de transacciones basadas en la confianza -

\footnotetext{
${ }^{10} \mathrm{El}$ proceso por el que la prohibición del préstamo de dinero con interés fue ganando fuerza al interior del mundo cristiano, especialmente católico, ha sido bastante documentado por Le Goff (2003).

${ }^{11}$ La misma familia Médicis estuvo expuesta varias veces a la acusación de usura.

${ }^{12}$ Los aspectos más oscuros del ejercicio del préstamo de interés por judíos a cristianos serán examinados en un trabajo posterior, desde la actitud que el Cristianismo adoptó hacia la usura.
} 
que hacía innecesaria la existencia de mecanismos coercitivos de cumplimiento para honrar los contratos- y que permitía subsistir a las comunidades dispersas. Un instrumento muy usado para satisfacer esas necesidades fue la letra de cambio, en la que el compromiso de devolución de un crédito naturalmente podía encubrir un tipo de interés al momento del pago. Pero no bastaba. Las operaciones eran cada vez más intrincadas y debía relativizarse la prohibición genérica a prestar o recibir prestado de otros judíos.

Pero ya existían exenciones talmúdicas. Una de ellas establecía la admisibilidad de que si un prestamista entregaba 100 unidades a un prestatario, que a su vez, lograba aumentar su valor a 200 , el acreedor tendría derecho a los 200 , siempre que hubiera pagado al prestatario alguna remuneración en consideración a su trabajo. Por otra parte, Rashi ${ }^{13}$ estableció que era lícito enviar a un amigo a contraer con un tercero un préstamo con interés dirigido a uno mismo, o que se podía facultar a un amigo para que diera dinero con interés a un tercero, en tanto el interés se prohibía sólo entre prestamista y prestatario, pero no entre sus respectivos representantes. El principio que el representante era equivalente al representado no podía ser aplicado en estos casos, porque el cobro de intereses era un delito penal y en materia penal nadie podía ser responsable por las acciones de otro.

\section{Formalización mosaica del préstamo de dinero con interés}

Con el tiempo, se estableció una forma estandarizada de legalización del interés (beneficio), conocida como Hetter iskah, que significa autorización para formar una asociación. Se elaboró una escritura, conocida como Shetar iskah, que apoyada en dos testigos, estipuló que el prestamista podía proporcionar una cierta suma de dinero al deudor para una empresa conjunta, mientras que el prestatario sólo administraría el negocio y garantizaría al prestamista su inversión contra toda pérdida y una cantidad fija de mínimo beneficio. La escritura también estableció que el prestatario pagaría una suma nominal como salario y acordaría con el prestamista compartir las eventuales pérdidas. Si se deseaba invalidar el acuerdo de distribución de pérdidas debido a la destrucción o carencia de las mercancías, esta debía probarse mediante una evidencia

13 1040-1105 dEC. 
normalmente inalcanzable. Esta forma de legalización del interés quedó tan consolidada que actualmente basta agregar al contrato las palabras al-pi Hetter iskah (según acuerdo de asociación permitido) para que sea lícito y existen diversas formas estandarizadas según tipos de contratos (Openheimer, 2010).

En cuanto a las operaciones de crédito con gentiles, el cobrarle intereses fue permitido a partir de la exención talmúdica de que no debe hacerse a menos que no haya otro medio de subsistencia:

Si hoy en día permitimos que se cobre interés a los gentiles, es porque el yugo y la carga que nos impone el rey y sus ministros no tiene fin, y todo lo que tomamos es el mínimo para nuestra subsistencia, y de cualquier manera estamos condenados a vivir en la medio de las naciones y no podemos ganarnos la vida de cualquier otra forma, excepto a través de transacciones de dinero con ellos, por lo que el cobro de intereses no debe ser prohibido.... (Ben-Zion Eliash, 2007).

Pero algo no estaba bien. Mientras las comunidades judías evolucionaban desde una condena muy severa a una actitud más permisiva hacia el préstamo de dinero con interés, las sociedades cristianas en las que se hallaban inmersas endurecían la actitud hacia lo que denominaban usura. Las enseñanzas de aquél rabino judío crucificado en tiempos de Tiberio habían calado profundo en el Occidente Europeo, desde la oración que supuestamente había enseñado a sus discípulos y que en una de sus partes decía: "dimmite nobis debita nostra sicut et nos dimmitimos debitoribus nostris", frase que fue reemplazada posteriormente por la Iglesia Católica a fines del siglo XIX y que significa: "perdónanos nuestras deudas, así como nosotros perdonamos a nuestros deudores".

\section{Conclusiones}

La rigurosa condena al préstamo de dinero con interés es una invención judía. A pesar que la práctica del préstamo de dinero con interés había sido permitida y regulada en las antiguas 
civilizaciones, la cultura judía fue la primera civilización que la condenó de un modo frontal y la llegó a prohibir de modo tan definitivo, abarcando en un sentido más amplio, el rechazo general a la obtención de un beneficio indebido bajo distintas vías.

Pero ese cambio trascendental de actitud no puede ser explicado al margen de transformaciones importantes en su contexto histórico. Sin el agravamiento de las fisuras internas y sin la concreción de las peores amenazas externas, la cultura judía podría haber cultivado la misma actitud ecléctica que tuvieron otras civilizaciones antiguas. A la inversa, sin el empeoramiento de las condiciones de existencia de las comunidades de la Diáspora luego del año $70 \mathrm{dEC}$ y la extrema necesidad de facilitar intercambios internos que resultaban críticos para la supervivencia, habría sido más difícil que se relajar prohibiciones cuya aplicación habría tenido consecuencias catastróficas. Repitiendo procedimientos que habían demostrado su validez, la adaptación de las viejas reglas se hizo de acuerdo al método casuístico utilizado por la tradición halájica. Ello permitió identificar excepciones cada vez más numerosas, adecuadamente fundadas en reglas éticas que buscaban la justicia y el bien común. Finalmente, la creación de nueva jurisprudencia desembocó en modelos formales que habilitaban el préstamo de dinero con interés bajo ciertas condiciones. En los hechos, la prohibición original, que se extendía a los ámbitos más diversos, quedó reducida a un núcleo ético muy delimitado, que no afectaba la cohesión del grupo.

Paradojalmente, mientras el proceso mosaico de flexibilización de la norma fue relativamente contemporáneo al endurecimiento progresivo de las normas cristianas, la Iglesia Cristiana reforzó sus principios en la materia inspirándose en fuentes mosaicas, que eran las únicas que habían creado un importante corpus teórico aplicado.

$\mathrm{Si}$ ambas civilizaciones hubieran desarrollado este proceso inverso de modo separado, probablemente esto no habría derivado en una terrible anatemización del pueblo judío. Pero la fortuna quiso que este cambio de actitud se diera en pequeñas y dispersas comunidades judías que sobrevivían insertas dentro de un océano cristiano que iba en la dirección opuesta. Como efecto de esa contradicción, la flexibilización interna de la prohibición y la mayor aceptación del libre ejercicio de la práctica con los gentiles, fue observada como una expresión de exacerbado 
egoísmo. Para la abrumadora mayoría de los europeos, mientras ellos se esforzaban por cumplir con reglas éticas que ponían freno al lucro excesivo, los judíos se convertían en el emblema de la avaricia. Mientras se consolidaba esa percepción, se fue asentando el estrato económico de la judeofobia. La invención se había vuelto contra el inventor.

\section{Bibliografía}

Armstrong, L. (2003) Usury. The Oxford Enciclopedia of Economic History. Joel Mokyr, editor general. Vol. 5. Oxford University Press. New York.

Attali, J. (2006). Los judios, el mundo y el dinero. Historia Económica del pueblo Judio. Buenos Aires, F.C.E.

Ben-Zion, E. (2007). Usury. Encyclopaedia Judaica (2007). Second edition. Volume 20, ToWei. Pp. 437-443. Fred Skolnik, Editor in Chief. Thompson Gale \& Keter Publishing House Ltd. Jerusalem.

Berger, P. (1989). La revolución capitalista. Barcelona. Península.

Castillo, A. (2012). Evolución histórica de la usura desde los origenes de la figura. Justicia y Derecho de los consumidores. $\mathrm{N}^{\mathrm{o}}$ 175, 23 de Septiembre 2012. Consulta: http://www.justiciayderecho.es/CONTENIDO/p2/GestionNoticias_500000647_ESP.asp (23-092012).

Clavero, B. (1984). Religión y Derecho: mentalidades y paradigmas. Historia, instituciones, documentos. $\mathrm{N}^{\mathrm{o}} 11$.

Dell'Aquila, E. (1992). El Dharma en el derecho tradicional de la India. Salamanca. Ediciones Universidad de Salamanca. 
Gelpí, R. y F. Julien-Labruyere (1998). Historia del crédito al consumo. Doctrinas y prácticas. Barcelona. Península.

Johnson, P. (2006). La Historia de los judíos. Barcelona. Zeta Bolsillo.

Kunicka-Michalska, B. (1994). La condena religiosa y jurídica de la usura. Eguzkilore, nº 8. San Sebastián.

Leites, E. (1994). From Tribal Brotherhood to Universal Otherhood: On Benjamin Nelson. Social Research. Vol. 61. No 4.

Le Goff, J. (2003). La bolsa y la vida: economía y religión en la Edad Media. Barcelona, Gedisa.

Nelson, B. (1969). The Idea of Usury: From Tribal Brotherhood to Universal Otherhood. Chicago y Londres.

Openheimer, D. (2010). La vida de tu hermano. Leyes de Ribit y Heter Iská. Buenos Aires. Editorial Adjut Israel.

Real Academia Española, Diccionario de la Lengua Española. 22ª edición.

Consultada en http://lema.rae.es/drae/?val=usura (22-09-2012)

Reed, Clyde, and Cliff Bekar (2003). Religious prohibitions against usury. Explorations in Economic History. № 40, 347-368.

Seldon, Arthur y F. G. Penance (1987). Diccionario de Economía. Una exposición alfabética de conceptos económicos y su aplicación. 2 vols. Barcelona. Orbis.

Tamari, M. (1987). With all your possessions. Jewish ethics and economic life”. New York. The Free Press. 
Visser, Wayne, and Alastair McIntosh (1998). A short review of the historical critique of usury. Accounting, Bussiness and Financial History. Vol. 8, № 2, 1998.

Weiss, A. (1968). El Talmud de Babilonia. Versión castellana dirigida y redactada por Mario Calés, sobre la base de la edición de Vilna. Buenos Aires. Acervo Cultural Editores. 